\title{
BMJ Open Perceptions of generic medication in the general population, doctors and pharmacists: a systematic review
}

\author{
Sarah Colgan, ${ }^{1}$ Kate Faasse, ${ }^{1}$ Leslie R Martin, ${ }^{2}$ Melika H Stephens, ${ }^{1}$ \\ Andrew Grey, ${ }^{3}$ Keith J Petrie ${ }^{1}$
}

To cite: Colgan S, Faasse K, Martin LR, et al. Perceptions of generic medication in the general population, doctors and pharmacists: a systematic review. BMJ Open 2015;5:e008915. doi:10.1136/bmjopen-2015008915

- Prepublication history and additional material is available. To view please visit the journal (http://dx.doi.org/ 10.1136/bmjopen-2015008915).

Received 27 May 2015 Revised 10 November 2015 Accepted 12 November 2015

CrossMark

\footnotetext{
${ }^{1}$ Department of Psychological Medicine, University of Auckland, Auckland, New Zealand

2Department of Psychology, La Sierra University, Riverside, California, USA ${ }^{3}$ Department of Medicine, University of Auckland, Auckland, New Zealand
}

Correspondence to Professor Keith J Petrie; kj.petrie@auckland.ac.nz

\section{ABSTRACT}

Objective: To investigate negative perceptions about generic medicines and evaluate the proportions of lay people, doctors and pharmacists who hold these perceptions.

Design: A systematic review of observational studies. Data sources: MEDLINE, EMBASE, Psyclnfo and Scopus.

Eligibility criteria: Quantitative data from crosssectional and prospective studies published in English after 1980, using self-report measures to evaluate perceptions about generic medicines, presented as percentages of the total sample assessed.

Results: After screening 2737 articles, 52 articles were included in the final analysis. A high proportion of doctors, pharmacists and lay people had negative perceptions of generics. Lay people were significantly more likely to view generics as less effective than branded medication (35.6\%, 95\% Cl $34.8 \%$ to $36.4 \%$ ) compared to doctors $(28.7 \%, 27.5 \%$ to $29.9 \%)$ and pharmacists $(23.6 \%, 21.2 \%$ to $26.2 \%), p<0.0001$. Pharmacists $(33.4 \%, 31.0 \%$ to $35.9 \%)$ were significantly more likely to believe generics were of inferior quality compared to branded medication than were doctors $(28.0 \%, 26.3 \%$ to $29.9 \%), p=0.0006$, and lay people $(25.1 \%, 24.2 \%$ to $26.0 \%), p<0.0001$. Doctors believed generics caused more side effects than branded medication $(24.4 \%, 22.2 \%$ to $26.9 \%)$, compared to pharmacists $(17.6 \%, 15.3 \%$ to $20.1 \%)$ and lay people (18.8\%, $17.8 \%$ to $19.8 \%), \mathrm{p}<0.0001$. Doctors $(28.5 \%, 26.9 \%$ to $30.2 \%)$ and pharmacists (25.4\%, $21.4 \%$ to $29.9 \%$ ) had significantly more safety concerns about generics than did lay people $(18.0 \%$, $17.0 \%$ to $19.0 \%), p \leq 0.0002$. A greater proportion of lay people felt negatively about generic substitution (34.0\%, 33.2\% to $34.9 \%$ ), compared to doctors $(24.1 \%, 22.0 \%$ to $26.4 \%)$ and pharmacists $(11.0 \%$, $9.6 \%$ to $12.7 \%), p<0.0001$. Rates of negative perceptions of generics do not appear to have changed substantially over time in the general population or among physician groups, $p \geq 0.431$, but such negative beliefs show a decreasing trend in pharmacists over the study period, $p=0.034$.

Conclusions: A significant proportion of doctors, pharmacists and lay people hold negative perceptions of generic medicines. It is likely these attitudes present barriers to the wider use of generics.

\section{Strengths and limitations of this study}

- This review is a comprehensive amalgamation of current research investigating perceptions of generic medicines among physicians, pharmacists and lay people.

- Our review used widely accepted methodology to evaluate the literature, and identified that a significant proportion of medical professionals and lay people hold negative perceptions of generic medicines.

- The review may have increased the risk of publication bias by only including studies that were published and available through the four databases we accessed, and hand searching was not performed.

- While there are a range of studies looking at attitudes of the general population and of doctors towards generics, there were only nine studies examining those views of pharmacists, which may have reduced the accuracy of the estimates in this group.

\section{INTRODUCTION}

Generic medicines have been available for many years and are routinely used to treat a wide range of acute and chronic illnesses. In order to be approved for use, a generic medicine must be bioequivalent to the originator product, and must be the same in terms of strength, safety and quality. ${ }^{1}$ While generic medicines are permitted to differ from their equivalent branded medicine in terms of colour, size, shape and excipient ingredients, they must be able to demonstrate bioequivalence to the originator product in terms of the rate and extent of absorption. ${ }^{2}{ }^{3}$ Generic formulations provide the same therapeutic effect as branded medicines at a much more economical price. ${ }^{4}$ For this reason, generic drugs have been increasingly popular as a method to reduce pressure on drug budgets, and they now make up an increasing percentage of dispensed drugs. ${ }^{5}$ 
Although generic medicine use has become more widespread, there is evidence that many doctors and pharmacists hold negative views of generics and resist prescribing generic medicines. ${ }^{6}{ }^{7}$ Many doctors oppose brand substitution, believing generic medicines to be inferior to their branded counterparts. ${ }^{7}$ In the UK, there was strong opposition when plans were proposed to introduce generic substitution into UK primary care, ${ }^{8}$ as well as controversy about using generic antiepileptic drugs $^{9}$ and generic pregabalin for pain control. ${ }^{10}$

A number of surveys have also shown sizable proportions of patients reporting negative views about generics, believing them to be less effective, of lower quality and unsuitable for treatment of major illnesses, as compared to their branded equivalents. ${ }^{11-14}$ Such negative views of generic medicines are important because they are likely to be associated with poorer health outcomes due to an association with higher side effect reporting and lower adherence. ${ }^{14}{ }^{15}$ If a substantial proportion of doctors, pharmacists and the general population hold negative views of generic drugs, it could represent an impediment to the widespread adoption of generic medication.

We conducted a systematic review to examine the attitudes towards generic drugs held by lay people, doctors and pharmacists. We extracted from the literature the proportion of participants who held negative views about how generics were perceived compared to their branded equivalent for the following five perceptions: drug effectiveness, drug quality, the likelihood of causing side effects, drug safety and attitude towards generic substitution or the process of replacing a branded medication with its generic equivalent.

\section{METHODS}

Inclusion criteria

To be eligible for inclusion in the review, studies had to include quantitative data presented as proportion of participants holding perceptions about generic medicines along any of the relevant dimensions. Studies could be either cross-sectional, mixed method or prospective in design. They also had to be in English, published in or after 1980, and had to include self-report measures to evaluate general perceptions about generic medicines, presented as percentages of the total sample assessed.

\section{Data sources and searches}

A systematic search of databases (MEDLINE, EMBASE, PsycINFO, Scopus) was conducted on 6 September 2015 , to retrieve relevant peer reviewed articles. The search strategy (see online supplementary appendix 1) employed for this review drew on common phrases and terms used in the literature concerning generic medicines, and included input from a specialist librarian. Keywords (appropriately truncated to allow a wide search) were combined with medical subject headings (MeSH) to comprehensively search four databases. The strategy was modified for Scopus due to a different search platform. Hand searching was not performed, but reference lists of identified systematic reviews and narrative reviews were reviewed to identify further studies.

\section{Data collection}

One author (SC) reviewed the titles and available abstracts for all identified citations, to determine relevance. Following the initial review, two of the authors (SC and MHS) independently reviewed full-text publications to make a final selection of included studies. A structured Excel spreadsheet was used to record relevant information and ensure uniformity of evaluation for each study. Extracted data included study characteristics including country of origin, sample type (doctor, pharmacist or lay population), sample size and proportions of participants with negative perceptions of generic medicines. The primary outcomes of this review were the proportions of participants reporting perceptions about generic medicines in terms of generic substitution, effectiveness, quality, side effects and safety.

\section{Quality assessment}

Two reviewers (KF and LRM) independently examined the full-text publications to complete a quality assessment. Raters independently categorised the articles as high, acceptable or poor quality, based on an evaluation of study design, participants ( $\mathrm{N}$, and type), demographics, recruitment method (random or other), exclusionary criteria, method of assessing perceptions (interview, questionnaire) and question quality (clarity, appropriate response options) (see online supplementary appendix 2). Consensus between the two reviewers was used to resolve any disagreement. Studies that were classified as being of poor quality were subsequently excluded. In line with Cochrane recommendations, we chose not to use a standardised scoring system to assess study quality. Calculating a summary score was not carried out so as to avoid assigning 'weights' to items on the scale that were unlikely to accurately reflect their relevance and that may have changed across different studies. ${ }^{16}$

\section{Statistical analyses}

From the full text of each paper, the total number of participants who took part in each study and the percentage who held perceptions of generic medicines across the five domains were extracted. These data were used to calculate the proportion of participants who reported negative views of generics compared to those who reported more accurate or positive views. These figures were summed to yield a total proportion of negative to neutral/positive views for each of the three population samples under investigation (general population, physician and pharmacist) for perceptions of effectiveness, quality, side effects, safety and substitution of generic medicines. Within each perception, the proportion of negative to neutral perceptions was compared across the three participant groups using $\chi^{2}$ tests of 
contingency tables with a Yates correction using GraphPad QuickCalcs software (http://graphpad.com/ quickcalcs/). As this approach required multiple comparisons, a conservative Bonferroni correction with an adjusted $\alpha$ level of $\mathrm{p}=0.0033(0.05 / 15$ tests $)$ was used.

For additional clarity and ease of interpretation in the presentation of the results, the extracted data were also used to calculate a weighted percentage (equivalent to the number of participants reporting negative views of generics out of the total number of respondents in each sample for each perception) of people holding negative perceptions across the relevant studies in each domain, assessed by generating a total sum of the number of participants with negative views, and calculating a percentage based on the total number of respondents in each group. Following this, modified Wald 95\% CIs were calculated for each weighted percentage value. ${ }^{17}$ The weighted percentages and $95 \%$ CIs were calculated using Microsoft Excel 2010 software.

Finally, Spearman's correlations were utilised in order to assess whether there had been a systematic change in perceptions of generic medicines over time. Correlations between publication year and the percentage of participants reporting negative perceptions were conducted to assess relationships between (1) the percentage of participants holding negative perceptions (across all participants and all five domains) and publication year, (2) the percentage of negative perceptions in each domain (across all participants) and publication year and (3) the percentage of negative perceptions across all domains within each of the three participant groups. Spearman's correlations were used because publication year was not normally distributed (almost $80 \%$ of the papers were published in the past 10 years), and were carried out using SPSS V.22 software. As this approach required multiple comparisons, a conservative Bonferroni correction with an adjusted $\alpha$ level of $\mathrm{p}=0.0055$ (0.05/9 tests) was used.

\section{RESULTS}

\section{Search results}

The systematic search process identified 2737 potentially relevant publications. The initial review eliminated 2582 of these publications, including duplicates, leaving 155 articles for full-text review. Of these, 73 articles were put forward for quality assessment. During this process, 21 studies were eliminated (figure 1). The publication dates for these studies ranged from 1987 through 2015, and included data from 27 countries. Additional characteristics of the studies included in the review are presented in table 1 for the general population, and in table 2 for doctors and pharmacists.

\section{Study quality}

The two raters initially made identical assessments in 48 of the 58 eligible papers, yielding a Cohen's $\mathrm{K}$ inter-rater reliability of $0.70, \mathrm{p}<0.001$, which indicates substantial agreement. ${ }^{18}$ Subsequently, each of the 10 cases on which raters disagreed was re-evaluated. For these studies, one rater had indicated acceptable and the other, either high or poor quality, but in no case was there a high-poor pairing. Discussion of rationale for the non-identical ratings was completed, and the raters came to a final agreement on each of the 10 cases. Of 58 studies, 29 were classified as high-quality, 23 were classified as acceptable and 6 were rated as being of poor quality. The six studies rated as poor quality were removed from the analysis.

\section{PERCEPTIONS OF GENERIC MEDICINES \\ Effectiveness}

A significantly greater proportion of the general population held the view that generic drugs were less effective than their brand name equivalents (5274/14817; $35.59 \%$ (95\% CI $(34.83 \%$ to $36.37 \%)$ ), compared to doctors $\quad(1450 / 5056 ; 28.68 \% \quad(95 \%$ CI $\quad(27.45 \%$ to $\left.29.94 \%)), \quad \chi^{2} \quad(1)=80.22, \quad \mathrm{p}<0.0001\right)$ and pharmacists $(264 / 1119 ; 23.60 \%$ (95\% CI $(21.20 \%$ to $26.18 \%)), \chi^{2}$ $(1)=65.57, p<0.0001)$. The proportion of physicians who held these negative views was significantly greater than pharmacists, $\chi^{2}(1)=11.57, p=0.0007$ (see figure 2 for graphical representation of results).

\section{Quality}

At least 25\% from each group reported the belief that the quality of generic medications is lower than that of branded drugs. Pharmacists reported the highest

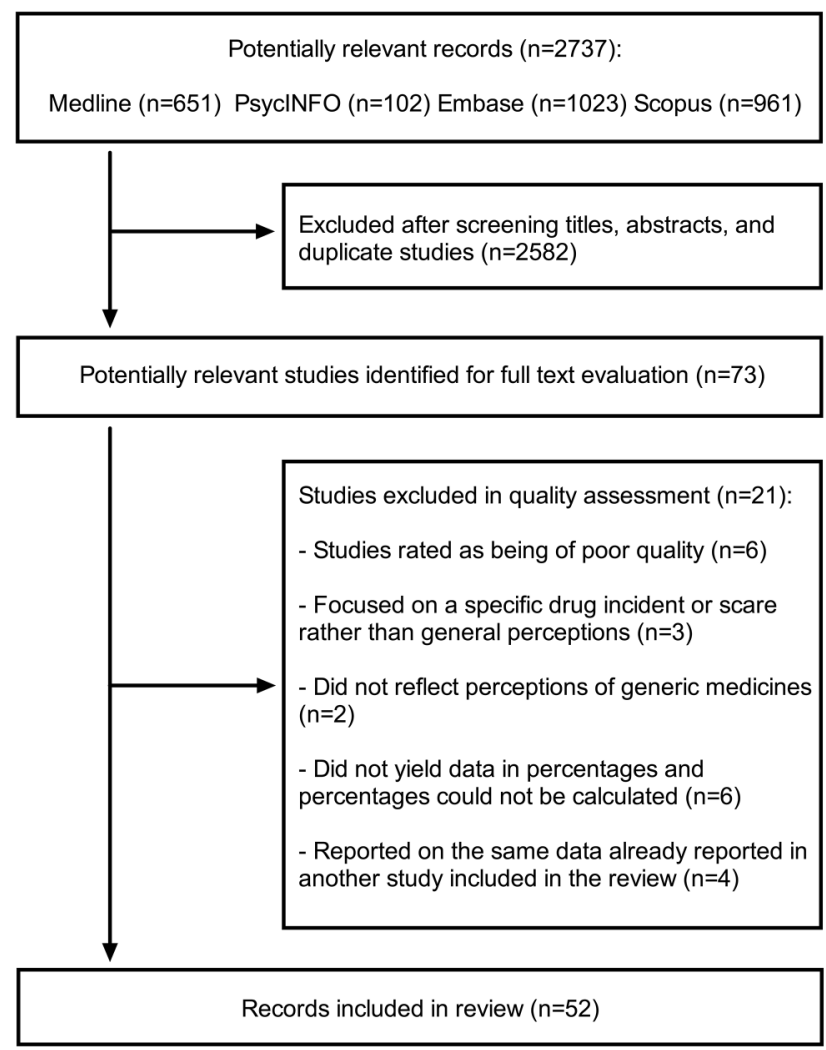

Figure 1 Flow chart of studies assessing perceptions of generics. 
Table 1 Selected studies assessing layperson perceptions of generic medicines

\begin{tabular}{|c|c|c|c|c|c|c|c|c|}
\hline Authors, date & Country & Sample & $\mathbf{N}$ & Substitution, \% & Effectiveness, \% & Quality, \% & Side effects, $\%$ & Safety \\
\hline Al-Gedadi et al, $2008^{21}$ & Malaysia & Lay & 396 & & 38.80 & 38.90 & 31.20 & \\
\hline Babar et al, $2011^{5}$ & New Zealand & Lay & 441 & & 22.90 & & 34.20 & \\
\hline Bertoldi et al, $2005^{23}$ & Brazil & Lay & 3182 & & & 30 & & \\
\hline Bradley et al, $1998^{24}$ & UK & Lay & 2276 & 43.90 & & & & \\
\hline Costa-Font et al, $2014^{25}$ & Spain & Lay & 2244 & 13.20 & & & & \\
\hline Dunne et al, $2014^{26}$ & Ireland & Lay & 42 & & 18 & 24 & & 5 \\
\hline Figueiras et al, $2009^{27}$ & Portugal & Lay & 819 & 40 & & & & \\
\hline Heikkilä et al, $2011^{28}$ & Finland & Lay & 1844 & & 19.10 & & & 15.50 \\
\hline Himmel et al, $2005^{13}$ & Germany & Lay & 804 & & & 36.70 & & \\
\hline Ibrahim et al, $2012^{29}$ & Australia & Lay & 503 & & 13 & 13 & 5 & 15 \\
\hline losifescu et al, $2008^{30}$ & USA & Lay & 315 & & 15.60 & & 11.60 & 20.10 \\
\hline Keenum et al, $2012^{31}$ & USA & Lay & 172 & & 23.30 & & 13.40 & \\
\hline Kobayashi et al, $2011^{32}$ & Japan & Lay & 1215 & 46 & & & & \\
\hline Kohli and Buller, $2013^{33}$ & USA & Lay & 160 & & 17 & 28 & & 9 \\
\hline Lebanova et al, $2012^{34}$ & Bulgaria & Lay & 216 & & 94 & 94 & & 94 \\
\hline Lira et al, $2014^{35}$ & Brazil & Lay & 278 & & 20.9 & 14.4 & & \\
\hline Nardi et al, $2015^{36}$ & Brazil & Lay & 5000 & & 30.4 & & & \\
\hline Omojasola et al, $2012^{37}$ & USA & Lay & 525 & & 6 & 7 & 29.60 & 3 \\
\hline Palagyi and Lassanova, $2008^{38}$ & Slovakia & Lay & 1777 & & 64 & 16.70 & & \\
\hline Perri et al, $1990^{39}$ & USA & Lay & 326 & & 13.50 & 11.40 & & 6.70 \\
\hline Piette et al, $2010^{40}$ & USA & Lay & 806 & & 31.60 & & & 28.50 \\
\hline Rathe et al, $2013^{41}$ & Denmark & Lay & 2476 & 14.50 & & & & \\
\hline Sansgiry and Bhosle, $2004^{42}$ & USA & Lay & 505 & & 10.92 & 7.40 & 5.08 & 6.08 \\
\hline Shrank et al, $2009^{43}$ & USA & Lay & 1047 & 26.10 & & & 9.50 & \\
\hline Sicras-Mainar and Navarro-Artieda, $2012^{44}$ & Spain & Lay (and physician) & 203 & & & 33.20 & 42.30 & \\
\hline Wong et al, $2014^{45}$ & Malaysia & Lay & 202 & & 23.8 & 23.3 & 23.8 & \\
\hline Yousefi et al, $2015^{46}$ & Iran & Lay & 1309 & 81 & 86 & & 21.4 & \\
\hline $\mathrm{N}$ reporting negative perceptions & & & & 3874 & 5274 & 2290 & 1054 & 942 \\
\hline Total N sampled & & & & 11386 & 14817 & 9119 & 5618 & 5242 \\
\hline Overall percentage & & & & 34.03 & 35.59 & 25.11 & 18.76 & 17.97 \\
\hline
\end{tabular}


Table 2 Selected studies assessing physician and pharmacist perceptions of generic medicines

\begin{tabular}{|c|c|c|c|c|c|c|c|c|}
\hline Authors, date & Country & Sample & $\mathbf{N}$ & Substitution, \% & Effectiveness, \% & Quality, \% & $\begin{array}{l}\text { Side } \\
\text { effects, \% }\end{array}$ & Safety, \% \\
\hline$\overline{\text { Andersson et al, } 2006^{47}}$ & Sweden & Physicians & 892 & 16.70 & & & & \\
\hline Bower and Burkett, $1987^{48}$ & USA & Physicians & 317 & 37.50 & & & & \\
\hline Brust et al, $1990^{49}$ & USA & Physicians & 145 & 45 & & & & \\
\hline Chua et al, $2010^{50}$ & Malaysia & Physicians & 87 & & 33 & & 41.40 & 52.90 \\
\hline Dosedel et al, $2014^{51}$ & $\begin{array}{l}\text { Czech } \\
\text { Republic }\end{array}$ & Physicians & 263 & & 39.1 & 46 & 37.3 & \\
\hline Dunne et al, $2014^{52}$ & Ireland & Physicians & 34 & & 11.8 & 8.8 & & 11.8 \\
\hline Fabiano et al, $2012^{53}$ & Italy & Physicians & 303 & & 17.50 & & 17.80 & \\
\hline Friedman et al, $1987^{54}$ & USA & Physicians & 245 & & 43.20 & & & \\
\hline Gossell-Williams, $2007^{55}$ & Jamaica & Physicians & 60 & 13 & 60 & & & \\
\hline Jamshed et al, $2012^{56}$ & Pakistan & Physicians & 206 & & 24.30 & 39.30 & 26.70 & 41.26 \\
\hline Kersnik and Peklar, $2006^{57}$ & Slovenia & Physicians & 117 & & 11.10 & & & \\
\hline Kumar et al, $2015^{58}$ & Malaysia & Physicians & 263 & & 51.7 & & 19.8 & \\
\hline Lewek et al, $2014^{59}$ & Poland & Physicians & 170 & & 28.8 & & 12.1 & \\
\hline Shrank et al, $2011^{7}$ & USA & Physicians & 506 & & 23.50 & 50 & & \\
\hline Sicras-Mainar and Navarro-Artieda, $2012^{44}$ & Spain & $\begin{array}{l}\text { Physician (and } \\
\text { lay) }\end{array}$ & 201 & & 40.80 & & & \\
\hline Theodorou et al, $2009^{60}$ & Greece & Physicians & 1204 & & 14.09 & 16.83 & & 15.37 \\
\hline & Cyprus & & 193 & & 5.70 & 7.25 & & 5.70 \\
\hline Tsiantou et al, $2009^{61}$ & Greece & Physicians & 1204 & & 40.70 & & & 41.90 \\
\hline$N$ reporting negative perceptions & & & & 341 & 1450 & 675 & 316 & 836 \\
\hline Total N sampled & & & & 1414 & 5056 & 2406 & 1292 & 2928 \\
\hline Overall percentage & & & & 24.11 & 28.68 & 28.04 & 24.43 & 28.54 \\
\hline Allenet and Barry, $2003^{62}$ & France & Pharmacists & 1000 & 10 & & & & \\
\hline Auta et al, $2014^{63}$ & Nigeria & Pharmacists & 154 & 7.10 & & 54.50 & & \\
\hline Awaisu et al, $2014^{64}$ & Qatar & Pharmacists & 108 & 27.70 & & & & \\
\hline Babar et al, $2011^{5}$ & New Zealand & Pharmacists & 360 & 10.60 & 50 & 65 & & 28 \\
\hline Chong et al, $2010^{65}$ & Australia & Pharmacists & 157 & & & & 13.40 & \\
\hline Chong et al, $2011^{6}$ & Malaysia & Pharmacists & 219 & & & 21.40 & 38.40 & \\
\hline Dunne et al, $2014^{66}$ & Ireland & Pharmacists & 44 & & 2.3 & 2.3 & & 4.5 \\
\hline Gupta, $1996^{67}$ & USA & Pharmacists & 100 & & 40 & & & \\
\hline Maly et al, $2013^{68}$ & Czech Rep & Pharmacists & 615 & & 7 & 16.10 & 11.20 & \\
\hline $\mathrm{N}$ reporting negative perceptions & & & & 179 & 264 & 465 & 174 & 103 \\
\hline Total $\mathrm{N}$ sampled & & & & 1622 & 1119 & 1392 & 991 & 404 \\
\hline Overall percentage & & & & 11.04 & 23.60 & 33.39 & 17.56 & 25.44 \\
\hline
\end{tabular}


Figure 2 Bar graph showing the percentage $(95 \% \mathrm{Cl})$ of participants (general population, physicians and pharmacists) reporting negative perceptions across the domains of effectiveness, quality, safety, side effects and substitution.

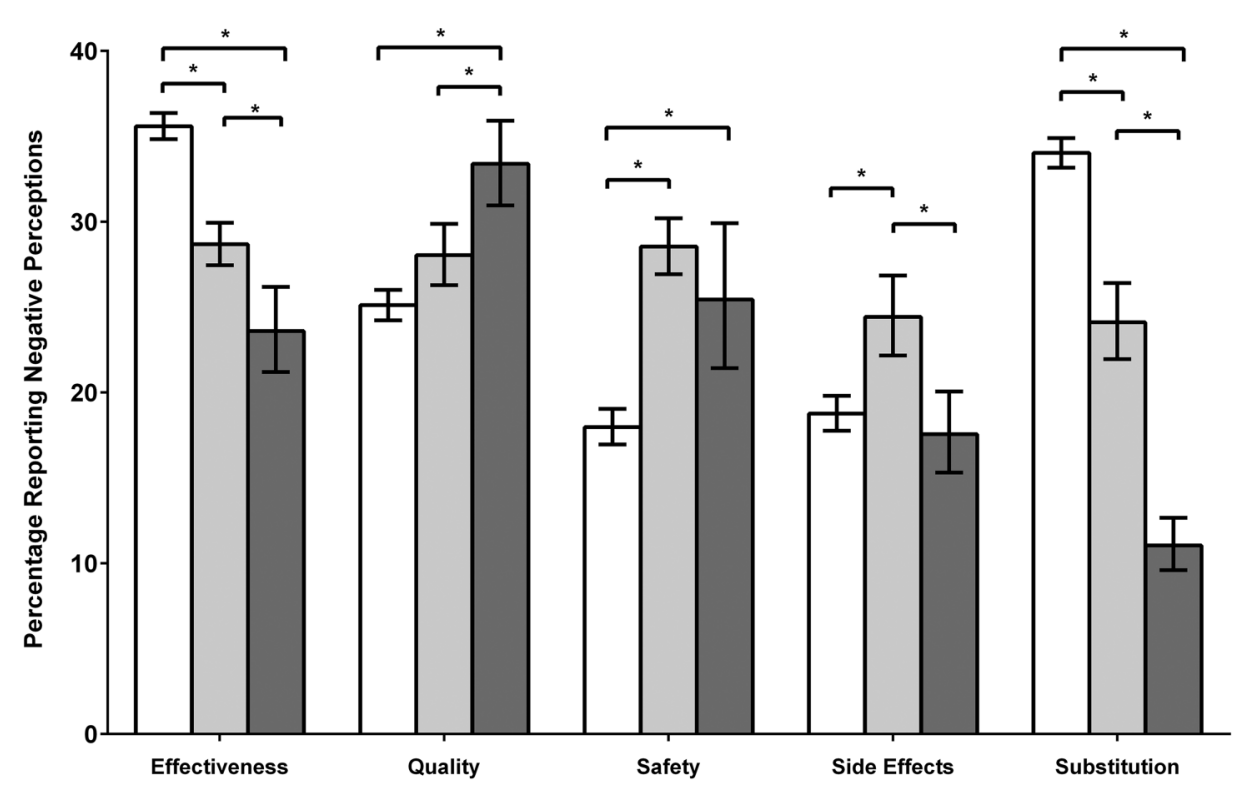

proportion of negative perceptions about quality (465/ 1392; $33.39 \%$ (95\% CI $(30.96 \%$ to $35.91 \%)$ ), a significantly greater proportion of negative perceptions than in either the physician sample $(625 / 2406 ; 28.04 \%(95 \%$ CI $(26.28 \%$ to $\left.29.87 \%)), \chi^{2}(1)=11.76, p=0.0006\right)$ or the general population $(2290 / 9119 ; 25.11 \% \quad(95 \%$ CI $(24.23 \%$ to $\left.26.01 \%)), \quad \chi^{2} \quad(1)=42.51, \quad \mathrm{p}<0.0001\right)$. Physicians and general population participants did not differ significantly from one another (after applying the Bonferroni correction), $\chi^{2}(1)=8.47, p=0.0036$.

\section{Safety}

A greater proportion of doctors (836/2928, 28.54\%, $95 \%$ CI $(26.93 \%$ to $30.20 \%)$ ) and pharmacists (103/ $404 ; 25.44 \%, 95 \%$ CI $(21.43 \%$ to $29.91 \%))$ held the perception that generic medicines were less safe to use than branded drugs than did the general population (942/ $5242 ; 17.97 \%, 95 \%$ CI $(16.96 \%$ to $19.04 \%)), \chi^{2}$ (1) $=122.93$ and 13.59, respectively, $\mathrm{p}<0.0001$ and 0.0002 . Physicians and pharmacists did not differ from one another with regard to negative perceptions of safety of generic drugs, $\chi^{2}(1)=1.49, p=0.22$.

\section{Side effects}

Physicians were the most likely to hold negative beliefs that side effects are more frequently caused by generic drugs in comparison to brand name alternatives, with one in four $(316 / 1292 ; 24.43 \%, 95 \%$ CI $(22.17 \%$ to $26.85 \%)$ ) endorsing these views. Physicians held significantly more inaccurate beliefs about side effects than did the general population groups $(1054 / 5618 ; 18.76 \%$, $95 \%$ CI $(17.76 \%$ to $19.80 \%)), \chi^{2} \quad(1)=21.09, \mathrm{p}<0.0001$, and pharmacists $(174 / 991 ; 17.56 \%(95 \%$ CI $(15.31 \%$ to $20.06 \%)), \chi^{2}(1)=15.43, p<0.0001$. There was no significant difference between the proportions of members of the general population and pharmacists reporting the perception that the side effects of generic drugs are higher than branded, $\chi^{2}(1)=0.73, p=0.3934$.

\section{Drug substitution}

Pharmacists had the lowest rates of negative perceptions about substitution of generic drugs for their brand name alternatives $(179 / 1622 ; 11.04 \%, 95 \%$ CI $(9.60 \%$ to $12.66 \%))$. The general population were most likely to report unfavourable attitudes towards substituting a branded medication with its generic equivalent (3874/ $11386 ; 34.03 \%$, 95\% CI $(33.16 \%$ to $34.90 \%))$, followed by physicians $(341 / 1414 ; 24.11 \%, 95 \%$ CI $(21.95 \%$ to $26.41 \%)$ ). Pharmacists had significantly lower rates of negative perceptions about generic drug substitution than both, members of the general population and doctors, $\chi^{2}(1)=348.72$ and 90.14 , respectively, $p<0.0001$. The general population samples held more negative perceptions of drug substitution than did physicians, $\chi^{2}(1)$ $=55.46, \mathrm{p}<0.0001$.

\section{Perceptions of generic medicines over time}

There was no significant overall relationship between publication year and the percentage of participants reporting negative perceptions of generic medicines across all participant groups and perception domains, $\mathrm{r}=-0.04, \mathrm{n}=115, \mathrm{p}=0.641$. Similarly, the percentage of negative perceptions held across the five domains did not demonstrate a significant correlation with publication year for beliefs about effectiveness, $\mathrm{r}=-0.03, \mathrm{n}=37$, $\mathrm{p}=0.853$; quality, $\mathrm{r}=-0.02, \mathrm{n}=25, \mathrm{p}=0.919$; safety, $\mathrm{r}=-0.20$, $\mathrm{n}=18, \mathrm{p}=0.424$; side effects, $\mathrm{r}=0.08, \mathrm{n}=20, \mathrm{p}=0.742$; or appropriateness of substitution, $\mathrm{r}=-0.11, \mathrm{n}=15, \mathrm{p}=0.693$. Finally, the change in the percentage of negative perceptions over time was assessed separately across the three participant groups. There was no significant correlation between negative perceptions and publication year for 
general population samples, $\mathrm{r}=0.10, \mathrm{n}=60, \mathrm{p}=0.431$; or physicians, $\mathrm{r}=-0.04, \mathrm{n}=37, \mathrm{p}=0.794$. There was a trend (after applying the Bonferroni correction) towards a significant correlation in pharmacists' overall negative perceptions and publication year, $\mathrm{r}=-0.50, \mathrm{n}=18, \mathrm{p}=0.034$. Although the result is not statistically significant, it indicates a possible reduction in overall reported negative perceptions in pharmacists over time.

\section{DISCUSSION}

\section{Key findings}

Our systematic review identified that a significant proportion of lay people, doctors and pharmacists hold negative perceptions of generic medicines, perceiving generics as less effective, less safe, inferior in quality and more likely to cause side effects compared to their branded equivalents. More than a quarter of doctors and the general population believed that generic drugs are less effective and of poorer quality than branded medication. A similar proportion of doctors and pharmacists had safety concerns about generics. While we did not identify any reduction in negative views of generics in doctors or lay people over the course of the review period, there was some evidence that the percentage of negative views of pharmacists had decreased.

These findings are important, as previous work has suggested that negative perceptions about generic medicines are major barriers to their acceptance and widespread usage. ${ }^{2}$ Furthermore, these findings have important implications for clinical practice, as pharmacists and medical practitioners are in a position where they can easily transmit their expectations about the effectiveness and side effects of generic medication to the patients under their care. ${ }^{19}{ }^{20}$ Research suggests that the majority of consumers learn about generic medicines from a physician or pharmacist, and this medical advice is critical to consumers' decision to take a generic medication. ${ }^{11} 21$

\section{Implications}

Generic medicines provide cost-effective alternatives to branded medicines, resulting in considerable savings to healthcare budgets. However, if consumers are poorly informed about their equivalence to branded medication, it is highly unlikely that generic medicines will be preferred over their branded equivalents. ${ }^{22}$ This review has identified that a significant proportion of health professionals and consumers have negative perceptions of generic medicines. There is clearly a need for interventions aimed at the general population and health professionals to target misperceptions of inferior quality, safety and efficacy-as well as to explain the reasons why generic medicines are cheaper than brand-name equivalents, the meaning of bioequivalence, and the testing and regulatory processes involved in approving a generic medicine for general use. ${ }^{2}$ Currently, there is a lack of research regarding what type of intervention may be effective in improving perceptions of generic medicines.

\section{Strengths and limitations}

This review is a comprehensive amalgamation of current research investigating perceptions of generic medicines among physicians, pharmacists and laypeople. The methods used to search and evaluate the literature are widely accepted. However, it is important to note that we may have increased the risk of publication bias by only including studies that were published and available through one of the four databases we accessed, and hand searching was not performed. In addition, we only reviewed studies that were published in English and we did not include qualitative studies, as we needed to compute the proportion of participant between physicians, pharmacists and lay groups. While there are a range of studies looking at the attitudes of the general population and doctors towards generics, there were only nine studies examining the views of pharmacists, and five of these studies had fewer than 200 participants. This may have reduced the accuracy of the estimates in this group.

\section{CONCLUSIONS}

These results suggest that there are a significant number of laypeople, doctors and pharmacists with concerns about the efficacy, safety and quality of generic medicines. The negative perceptions of doctors and pharmacists are likely to be barriers to a wider acceptance of generics, as health professionals have a strong influence on patients' decisions to take generic medicine. Further work is needed on how interventions for medical professionals and for the public can reduce negative attitudes about efficacy, safety and side effects, in order to increase the acceptability of generic prescribing and substitution.

Twitter Follow Keith Petrie at @KeithPetrie and Leslie Martin at @LeslieRMartin1

Contributors SC and KJP designed the study. SC and MHS searched the literature and extracted the data. KF and LRM conducted the quality analysis, and analysed and interpreted the data. SC, KF and KJP drafted the manuscript. AG, MHS and LRM contributed to the critical revision of the manuscript. SC and KJP are the guarantors.

Funding This research was funded by the Auckland Medical Research Foundation and Pharmac (the New Zealand Government's Pharmaceutical Management Agency).

Competing interests None declared.

Provenance and peer review Not commissioned; externally peer reviewed.

Data sharing statement No additional data are available.

Open Access This is an Open Access article distributed in accordance with the Creative Commons Attribution Non Commercial (CC BY-NC 4.0) license, which permits others to distribute, remix, adapt, build upon this work noncommercially, and license their derivative works on different terms, provided the original work is properly cited and the use is non-commercial. See: http:// creativecommons.org/licenses/by-nc/4.0/ 


\section{REFERENCES}

1. World Health Organisation. Trade, foreign policy, diplomacy and health: generic drugs. http://www.who.int/trade/glossary/story034/en/ (accessed 18 Mar 2014)

2. Alrasheedy AA, Hassali MA, Stewart K, et al. Patient knowledge, perceptions, and acceptance of generic medicines: a comprehensive review of the current literature. Patient Intell 2014;6:1-29.

3. Dunne S, Shannon B, Dunne C, et al. A review of the differences and similarities between generic drugs and their originator counterparts, including economic benefits associated with usage of generic medicines, using Ireland as a case study. BMC Pharmacol Toxicol 2013;14:1.

4. Howland $\mathrm{RH}$. What makes a generic medication generic? $J$ Psychosoc Nurs Ment Health Serv 2009;47:17-20.

5. Babar ZU, Grover P, Stewart J, et al. Evaluating pharmacists' views, knowledge, and perception regarding generic medicines in New Zealand. Res Social Adm Pharm 2011;7:294-305.

6. Chong CP, Hassali MA, Bahari MB, et al. Exploring community pharmacists' views on generic medicines: a nationwide study from Malaysia. Int J Clin Pharm 2011;33:124-31.

7. Shrank WH, Liberman JN, Fischer MA, et al. Physician perceptions about generic drugs. Ann Pharmacother 2011;45:31-8.

8. Ferner R, Lenney W, Marriott J, et al. Controversy over generic substitution. BMJ 2010;340:c1341-3.

9. Shaw SJ, Hartman AL. The controversy over generic antiepileptic drugs. J Pediatr Pharmacol Ther 2010;15:81-93.

10. Wise J. Doctors are warned not to prescribe generic pregabalin for pain control. BMJ 2015;350:h1724.

11. Babar ZU, Stewart J, Reddy S, et al. An evaluation of consumers' knowledge, perceptions and attitudes regarding generic medicines in Auckland. Pharm World Sci 2010;32:440-8.

12. Al Ameri MN, Whittaker C, Tucker A, et al. A survey to determine the views of renal transplant patients on generic substitution in the UK. Transpl Int 2011;24:770-9.

13. Himmel W, Simmenroth-Nayda A, Niebling W, et al. What do primary care patients think about generic drugs? Int $J$ Clin Pharmacol Ther 2005;43:472-9.

14. Faasse K, Cundy T, Gamble G, et al. The effect of an apparent change to a branded or generic medication on drug effectiveness and side effects. Psychosom Med 2013;75:90-6.

15. Håkonsen $\mathrm{H}$, Eilertsen $\mathrm{M}$, Borge $\mathrm{H}$, et al. Generic substitution: additional challenge for adherence in hypertensive patients? Curr Med Res Opin 2009;25:2515-21.

16. Higgins JPT, Green S. Cochrane handbook for systematic reviews of interventions. Version 5.1.0. Cochrane Collaboration, 2009.

17. Agresti A, Coull BA. Approximate is better than "exact" for interval estimation of binomial proportions. Am Statistician 1998;52:119-26.

18. Landis JR, Koch GG. The measurement of observer agreement for categorical data. Biometrics 1977;33:159-74.

19. Faasse K, Petrie KJ. The nocebo effect: Patient expectations and medication side effects. Postgrad Med J 2013;89:540-6.

20. Bingel U, Wanigasekera $\mathrm{V}$, Wiech $\mathrm{K}$, et al. The effect of treatment expectation on drug efficacy: imaging the analgesic benefit of the opioid remifentanil. Sci Transl Med 2011;3:70ra14.

21. Al-Gedadi NA, Hassali MA, Shafie AA, et al. A pilot survey on perceptions and knowledge of generic medicines among consumers in Penang, Malaysia. Pharm Prac 2008;6:93-7.

22. Hassali MA, Shafie AA, Jamshed $S$, et al. Consumers' views on generic medicines: a review of the literature. Int $J$ Pharm Pract 2009;17:79-88.

23. Bertoldi AD, Barros AJ, Hallal PC. Generic drugs in Brazil: known by many, used by few. Cad Saude Publica 2005;21:1808-15.

24. Bradley CP, Riaz A, Tobias RS, et al. Patient attitudes to over-the-counter drugs and possible professional responses to self-medication. Fam Pract 1998;15:44-50.

25. Costa-Font J, Rudisill C, Tan S, et al. Brand loyalty, patients and limited generic medicines uptake. Health Policy 2014:116:224-33.

26. Dunne S, Shannon B, Dunne C, et al. Patient perceptions of generic medicines: a mixed-methods study. Patient 2014;7:177-85

27. Figueiras MJ, Alves NC, Marcelino D, et al. Assessing lay beliefs about generic medicines: development of the generic medicines scale. Psychol Health Med 2009;14:311-21.

28. Heikkilä $\mathrm{R}$, Mäntyselkä $\mathrm{P}$, Ahonen $\mathrm{R}$, et al. Do people regard cheaper medicines effective? Population survey on public opinion of generic substitution in Finland. Pharmacoepidemiol Drug Saf 2011;20:185-91.

29. Ibrahim R, McKinnon RA, Ngo SN, et al. Knowledge and perceptions of community patients about generic medicines. JPPR 2012;42:283-6.
30. Iosifescu A, Halm EA, McGinn T, et al. Beliefs about generic drugs among elderly adults in hospital-based primary care practices. Patient Educ Couns 2008;73:377-83.

31. Keenum AJ, Devoe JE, Chisolm DJ, et al. Generic medications for you, but brand-name medications for me. Res Social Adm Pharm 2012;8:574-8.

32. Kobayashi E, Karigome H, Sakurada T, et al. Patients' attitudes towards generic drug substitution in Japan. Health Policy 2011;99:60-5

33. Kohli E, Buller A. Factors influencing consumer purchasing patterns of generic versus brand name over-the-counter drugs. South Med J 2013;106:155-60.

34. Lebanova H, Manolov D, Getov I, et al. Patients' attitude about generics-Bulgarian perspective. Marmara Pharm J 2012;1:36-40.

35. Lira CA, Oliceira JN, Adrade Mdos S, et al. Knowledge, perceptions and use of generic drugs: a cross sectional study. Einstein (São Paulo) 2014;12:267-73

36. Nardi EP, Ferraz MB, Pinheiro GR, et al. Perceptions of the population regarding generic drugs in Brazil: a nationwide survey. BMC Public Health 2015;15:117.

37. Omojasola A, Hernandez M, Sansgiry S, et al. Perception of generic prescription drugs and utilization of generic drug discount programs. Ethn Dis 2012;22:479-85.

38. Palagyi M, Lassanova M. Patients attitudes towards experience with use of generics in Slovakia, performance of generic substitution. Bratisl Lek Listy 2008;109:324-8.

39. Perri M,III, Wolfgang AP, Jankel CA, et al. Georgia consumers' awareness and perceptions of generic drugs after the scandals. Am Pharm 1990;NS30:33-6.

40. Piette JD, Heisler M, Harand A, et al. Beliefs about prescription medications among patients with diabetes: Variation across racial groups and influences on cost-related medication underuse. $J$ Health Care Poor Underserved 2010;21:349-61.

41. Rathe J, Larsen $\mathrm{P}$, Andersen $\mathrm{M}$, et al. Associations between generic substitution and patients' attitudes, beliefs and experiences. Eur $J$ Clin Pharmacol 2013;69:1827-36.

42. Sansgiry SS, Bhosle MJ. Consumer perceptions of generic drug substitution practices in the USA. JPPR 2004;34:262-6.

43. Shrank WH, Cox ER, Fischer MA, et al. Patients' perceptions of generic medications. Health Aff 2009;28:546-56.

44. Sicras-Mainar A, Navarro-Artieda R. Physicians' and patients opinions on the use of generic drugs. J Pharmacol Pharmacother 2012;3:268-70.

45. Wong ZY, Hassali MA, Alrasheedy AA, et al. Patients' beliefs about generic medicines in Malaysia. Age 2014;12:474.

46. Yousefi N, Mehralian G, Peiravian F, et al. Consumers' perception of generic substitution in Iran. Int J Clin Pharm 2015;37:497-503.

47. Andersson K, Jörgensen T, Carlsten A, et al. Physicians' opinions and experiences of the pharmaceutical benefits reform. Scand $J$ Public Health 2006;34:654-9.

48. Bower AD, Burkett GL. Family physicians and generic drugs: a study of recognition, information sources, prescribing attitudes, and practices. J Fam Pract 1987:24:612-16.

49. Brust M, Hawkins CF, Grayson D, et al. Physicians' attitudes toward generic drug substitution by pharmacists. Tex Med 1990;86:45-9.

50. Chua GN, Hassali MA, Shafie AA, et al. A survey exploring knowledge and perceptions of general practitioners towards the use of generic medicines in the northern state of Malaysia. Health Policy 2010;95:229-35.

51. Dosedel M, Maly J, Kubena A, et al. Opinions of Czech general practitioners on generic drugs and substitution. Cent Eur J Med 2014;9:830-8

52. Dunne SS, Shannon B, Cullen W, et al. Beliefs, perceptions and behaviours of GPs towards generic medicines. Fam Pract 2014;31:467-74.

53. Fabiano V, Mameli C, Cattaneo D, et al. Perceptions and patterns of use of generic drugs among Italian family pediatricians: first round results of a web survey. Health Policy 2012;104:247-52.

54. Friedman D, Jaffe A, Steinhardt S. Physicians' attitudes toward and knowledge about generic drug substitution. NY State J Med 1987;87:539-42.

55. Gossell-Williams M. Generic substitutions: a 2005 survey of the acceptance and perceptions of physicians in Jamaica. West Indian Med J 2007;56:458-63.

56. Jamshed $\mathrm{SQ}$, Ibrahim MI, Hassali MA, et al. Perception and attitude of general practitioners regarding generic medicines in Karachi, Pakistan: a questionnaire based study. South Med Rev 2012:5:22-30.

57. Kersnik J, Peklar J. Attitudes of Slovene general practitioners towards generic drug prescribing and comparison with international studies. J Clin Pharm Ther 2006;31:577-83. 
58. Kumar R, Hassali MA, Saleem F, et al. Knowledge and perceptions of physicians from private medical centres towards generic medicines: a nationwide survey from Malaysia. J Pharm Policy Pract 2015;8:11.

59. Lewek P, Smigielski J, Kardas $\mathrm{P}$, et al. Factors affecting the opinions of family physicians regarding generic drugs - a questionnaire based study. Bosn J Basic Med Sci 2014;15:45-50.

60. Theodorou M, Tsiantou V, Pavlakis A, et al. Factors influencing prescribing behaviour of physicians in Greece and Cyprus: results from a questionnaire based survey. BMC Health Serv Res 2009;9:150.

61. Tsiantou V, Zavras D, Kousoulakou H, et al. Generic medicines: Greek physicians' perceptions and prescribing practices. J Clin Pharm Ther 2009;34:547-54.

62. Allenet $\mathrm{B}, \mathrm{Barry} \mathrm{H}$. Opinion and behaviour of pharmacists towards the substitution of branded drugs by generic drugs: Survey of 1,000 French community pharmacists. Pharm World Sci 2003;25:197-202.

63. Auta A, Bala ET, Shalkur D, et al. Generic medicine substitution: a cross-sectional survey of the perception of pharmacists in north-central, Nigeria. Med Prin Pract

2014;23:53-8.

64. Awaisu A, Kheir N, Ibrahim Ml, et al. Knowledge, attitudes, and practices of community pharmacists on generic medicines in Qatar. Int J Clin Pharm 2014:36:394-404

65. Chong CP, Hassali MA, Bahari MB, et al. Evaluating community pharmacists' perceptions of future generic substitution policy implementation: a national survey from Malaysia. Health Policy 2010;94:68-75.

66. Dunne SS, Shannon B, Cullen W, et al. Perceptions and attitudes of community pharmacists towards generic medicines. J Manag Care Pharm 2014;20:1138-46.

67. Gupta PB. Survey of pharmacists: impact of the generic drug scandal and implications for marketing generic drugs. Health Mark $Q$ 1996;13:109-20.

68. Maly J, Dosedel M, Kubena A, et al. Analysis of pharmacists' opinions, attitudes and experiences with generic drugs and generic substitution in the Czech Republic. Acta Pol Pharm 2013;70:923-31. 